\title{
Neonatal Adaptation in Infants Prenatally Exposed to Antidepressants- Clinical Monitoring Using Neonatal Abstinence Score
}

\author{
Lisa Forsberg ${ }^{1,2 *}$, Lars Navér ${ }^{1,2}$, Lars L. Gustafsson ${ }^{3}$, Katarina Wide ${ }^{1,2}$ \\ 1 Department of Pediatrics, Karolinska University Hospital, Stockholm, Sweden, 2 Department of Clinical Science, Intervention and Technology (CLINTEC), Karolinska \\ Institutet, Stockholm, Sweden, 3 Department of Laboratory Medicine, Division of Clinical Pharmacology, Karolinska Institutet, Stockholm, Sweden
}

\begin{abstract}
Background: Intrauterine exposure to antidepressants may lead to neonatal symptoms from the central nervous system, respiratory system and gastrointestinal system. Finnegan score (Neonatal Abstinence Score, NAS) has routinely been used to assess infants exposed to antidepressants in utero.

Aim: The purpose was to study neonatal maladaptation syndrome in infants exposed to selective serotonin reuptake inhibitors (SSRI) or serotonin-norepinephrine reuptake inhibitors (SNRI) in utero.

Method: Retrospective cohort study of women using antidepressants during pregnancy and their infants. Patients were identified from the electronic health record system at Karolinska University Hospital Huddinge containing pre-, peri- and postnatal information. Information was collected on maternal and infant health, social factors and pregnancy. NAS sheets were scrutinized.

Results: 220 women with reported $3^{\text {rd }}$ trimester exposure to SSRIs or SNRIs and who gave birth between January 2007 and June 2009 were included. Seventy seven women (35\%) used citalopram, 76 used (35\%) sertraline, 34 (15\%) fluoxetine and 33 (15\%) other SSRI/SNRI. Twenty-nine infants (13\%) were admitted to the neonatal ward, 19 were born prematurely. NAS was analyzed in 205 patients. Severe abstinence was defined as eight points or higher on at least two occasions (on a scale with maximum 40 points), mild abstinence as 4 points or higher on at least two occasions. Seven infants expressed signs of severe abstinence and $46(22 \%)$ had mild abstinence symptoms. Hypoglycemia (plasma glucose $<2.6 \mathrm{mmol} / \mathrm{L}$ ) was found in 42 infants (19\%).

Conclusion: Severe abstinence in infants prenatally exposed to antidepressants was found to be rare (3\%) in this study population, a slightly lower prevalence than reported in previous studies. Neonatal hypoglycemia in infants prenatally exposed to antidepressant may however be more common than previously described.
\end{abstract}

Citation: Forsberg L, Navér L, Gustafsson LL, Wide K (2014) Neonatal Adaptation in Infants Prenatally Exposed to Antidepressants- Clinical Monitoring Using Neonatal Abstinence Score. PLoS ONE 9(11): e111327. doi:10.1371/journal.pone.0111327

Editor: Gabriele Fischer, Medical University of Vienna, Austria

Received May 26, 2014; Accepted September 29, 2014; Published November 3, 2014

Copyright: (c) 2014 Forsberg et al. This is an open-access article distributed under the terms of the Creative Commons Attribution License, which permits unrestricted use, distribution, and reproduction in any medium, provided the original author and source are credited.

Data Availability: The authors confirm that all data underlying the findings are fully available without restriction. The data cannot be made available in the manuscript, the supplemental files or in a public repository due to ethical restrictions from the Regional Ethical Review Board in Stockholm. Data files will be made available after completion of a supplementary application to the Regional Ethical Review Board in Stockholm. To request data, contact Lisa Forsberg (first author) and the Regional Ethical Review Board in Stockholm, phone number +46852487000 or +468524800 00, www.epn.se.

Funding: Funding provided by Swedish Research Council, grant number 2011-3440 www.vr.se to LLG, Swedish Research Council, grant number 2012-3466, www.vr.se to KW, The Mayflower Foundation, www.majblomman.se to KW LF and The Samariten Foundation, www.stiftelsensamariten.se to LF KW. The funders had no role in study design, data collection and analysis, decision to publish, or preparation of the manuscript.

Competing Interests: The authors have declared that no competing interests exist.

* Email: lisa.forsberg.1@ki.se

\section{Background}

Psychiatric conditions are common during and after pregnancy. A large US study showed a prevalence of $13 \%$ for both mood and for anxiety disorders in pregnant or postpartum women [1]. Antidepressants are commonly used to treat major depressive disorders as well as other psychiatric conditions such as anxiety and obsessive compulsive disorders. Selective serotonin reuptake inhibitors (SSRIs) are the most prescribed group of antidepressants, also in pregnant women [2]. Serotonin norepinephrine reuptake inhibitors (SNRIs) are also used during pregnancy with similar effects on prenatally exposed children as SSRIs [3]. A population based register study showed that $3 \%$ of all pregnant women in Sweden used antidepressants, mainly SSRIs, three months prior to conception, whereas the numbers decreased during pregnancy, down to $1 \%$ in the third trimester [2]. In Denmark, there has been an increase in antidepressant use in pregnancy. In 1997, $0.2 \%$ of all pregnant women had at some point during pregnancy been using antidepressants, in 2010 this figure had increased to $3.2 \%$ [4].

Use of paroxetine during early pregnancy has been linked to an increased risk of heart malformations, OR 1.66 (95\% CI 1.09 to 
2.53) and hypospadias, OR 2.45 (95\% CI 1.12 to 4.64) [5]. A Canadian study found a significantly increased risk of heart malformations only in infants exposed to paroxetine daily doses higher than $25 \mathrm{mg}$ [6]. A neonatal maladaptation syndrome in infants exposed to SSRIs during late pregnancy is well known. It includes symptoms such as jitteriness, feeding problems, respiratory distress, hypoglycemia $[5,7,8]$. The relative risk of persistent pulmonary hypertension, a potentially life threatening condition, is increased in infants prenatally exposed to SSRI, from 1.2 per 1000 live births in unexposed infants to 3 per 1000 live births in SSRI exposed neonates [9]. Maternal illness (depression, anxiety) may also contribute to milder neonatal symptoms usually resolving within a week [10]. The mode of action for neonatal maladaptation after SSRI/SNRI exposure is largely unknown. 'Abstinence' due to the discontinued distribution of the pharmacological substance at delivery as well as serotonergic overstimulation has been suggested [8].

Finnegan score, or Neonatal Abstinence Score sheet (NAS) was originally developed to diagnose abstinence in infants prenatally exposed to opioids [11], but has also been used to assess neonatal symptoms in SSRI exposed infants [12].

As stated above, antidepressants during pregnancy is a common clinical problem, of growing significance. Conducting clinical research in the field of perinatal pharmacological exposure is complicated due to many ethical considerations and an abundance of potential confounders. This study was initiated to shed light on the occurrence of neonatal abstinence/maladaptation after SSRI/ SNRI exposure in utero and its prevalence, timing, severity and clinical features of this known but inadequately described condition.

\section{Methods}

The study design was a retrospective cohort study. The study patients were identified in the integrated electronic health record used in the delivery and prenatal care units as well as for outpatient maternal visits (Obstetrix ${ }^{\mathrm{R}}$ 2.12.01.100, Siemens AG, Munich, Germany). Patients with diagnostic codes for psychiatric illness during pregnancy and exposure to fetus of pharmacological substances were selected as the study population.

Women fulfilling these criteria and who had been giving birth at the Karolinska University Hospital Huddinge between 1 January, 2007 and 30 June, 2009 were included. Patients with reported substance abuse (alcohol or drugs) or use of certain kinds of neurotropic medication (antiepileptic drugs, lithium, opioids) were excluded. Information about substance abuse was reported in the patient records but not systematically confirmed through urine toxicology or breathalyser. Patients where substantial parts of the prenatal care records could not be retrieved were also excluded.

Information regarding social situation, prenatal medication (antidepressants and other pharmacological substances), health status and pregnancy related complications were retrieved from the prenatal part of the electronic health record $\left(\right.$ Obstetrix $\left.{ }^{R}\right)$. The information on use of antidepressants, bensodiazepines and other pharmacological substances was based on self-report or stated by the prescribing physician in the patient records. Obstetrix ${ }^{\mathrm{R}}$ was also used to extract clinical information about the delivery, infant health including health problems in the maternal ward and admission to the neonatal ward. During the study period, all infants where the mother had reported antidepressant use during late pregnancy were routinely observed at the maternal ward for at least 72 hours and modified Finnegan score used regularly to detect signs of abstinence. The assessments were extracted from the electronic health record system and analyzed.
A modified Finnegan score or Neonatal Abstinence Score (NAS) in Swedish was used in this study [13]. A version re-translated into English from Swedish is showed in Fig. 1. The assessment includes four categories: central nervous system (CNS), respiratory, gastrointestinal and 'other symptoms'. The maximum score for each scoring occasion is 40 points, of which 21 are related to CNS items. Neonatal abstinence was in this study classified as either mild (score 4 and above on at least two occasions) or severe (score 8 and above on at least two occasions). A similar classification has been used previously [12].

Population data regarding rates of neonatal admission, rates of smoking in early pregnancy, caesarian section and maternal age with regard to the Stockholm county area and Karolinska University Hospital Huddinge were obtained from the Swedish Neonatal Quality Register (SNQ) and from the statistical unit at National Swedish Board of Health and Welfare. These data were obtained as processed data [14].

Statistical analyses were performed with Statistica ${ }^{\mathrm{R}}$ 64, version 12 (StatSoft Scandinavia AB, Uppsala, Sweden). In the comparison between groups, chi square Pearson's test, ANOVA (Analysis of Variance) or Kruskal Wallis was used. Ordinal regression was used in the comparison of different levels of abstinence. Logistic regression or linear regression was used in the multiple regression models.

The study was a retrospective evaluation, based on patient records and conducted several years after the delivery of the infants. Neither written nor verbal informed consent was obtained. Data from patient records were extracted by one researcher and only relevant parts of the records were entered. The data was recorded in a data file with the confidentiality that is applied to patient records. Every individual was given a code number to strengthen the protection of confidentiality. No individual is possible to identify from the report. The study design was approved by the Regional Ethical Review Board in Stockholm (no. 2010/686-31).

\section{Results}

During the study period of 2.5 years between January 1, 2007 and June 30, 2009, 365 patients with diagnostic code for pharmacological exposure to fetus and psychiatric illness during pregnancy delivered at Karolinska University Hospital Huddinge. Use of SSRI/SNRI was confirmed in 277 patients. Thirty-four were excluded due to confirmed (or strongly suspected) substance abuse, opioid use or use of other psychotropic medication such as lithium or antipsychotics. Twenty patients could not be included due to missing data. One pair of twins was excluded. Two hundred and twenty patients remained; 54 gave birth in 2007, 103 in 2008 and 63 during the first six months of 2009. During 2007, 2008 and 2009 a total of 13755 infants were born at Karolinska University Hospital Huddinge [14].

Table 1 describes the women in the cohort with regard to social factors, health status and reported medication during pregnancy (antidepressants and other); divided by reported third trimester antidepressant use. The most common exposures were citalopram, sertraline and fluoxetine (Table 1). The remaining patients, in all $33(15 \%)$, were exposed to escitalopram (13 patients), venlafaxine (11 patients), paroxetine (8 patients) and duloxetine (one patient). Depression and anxiety disorders were the most common reasons for antidepressant use.

Cigarette smoking in early pregnancy in the cohort was $13 \%$ (for all 2.5 years) as compared to $5.4 \%$ in $2007,4.9 \%$ in 2008 and $4.7 \%$ in 2009 for women in early pregnancy in the whole Stockholm area. BMI was higher in the cohort, $24.4 \mathrm{~kg} / \mathrm{m}^{2}$, 


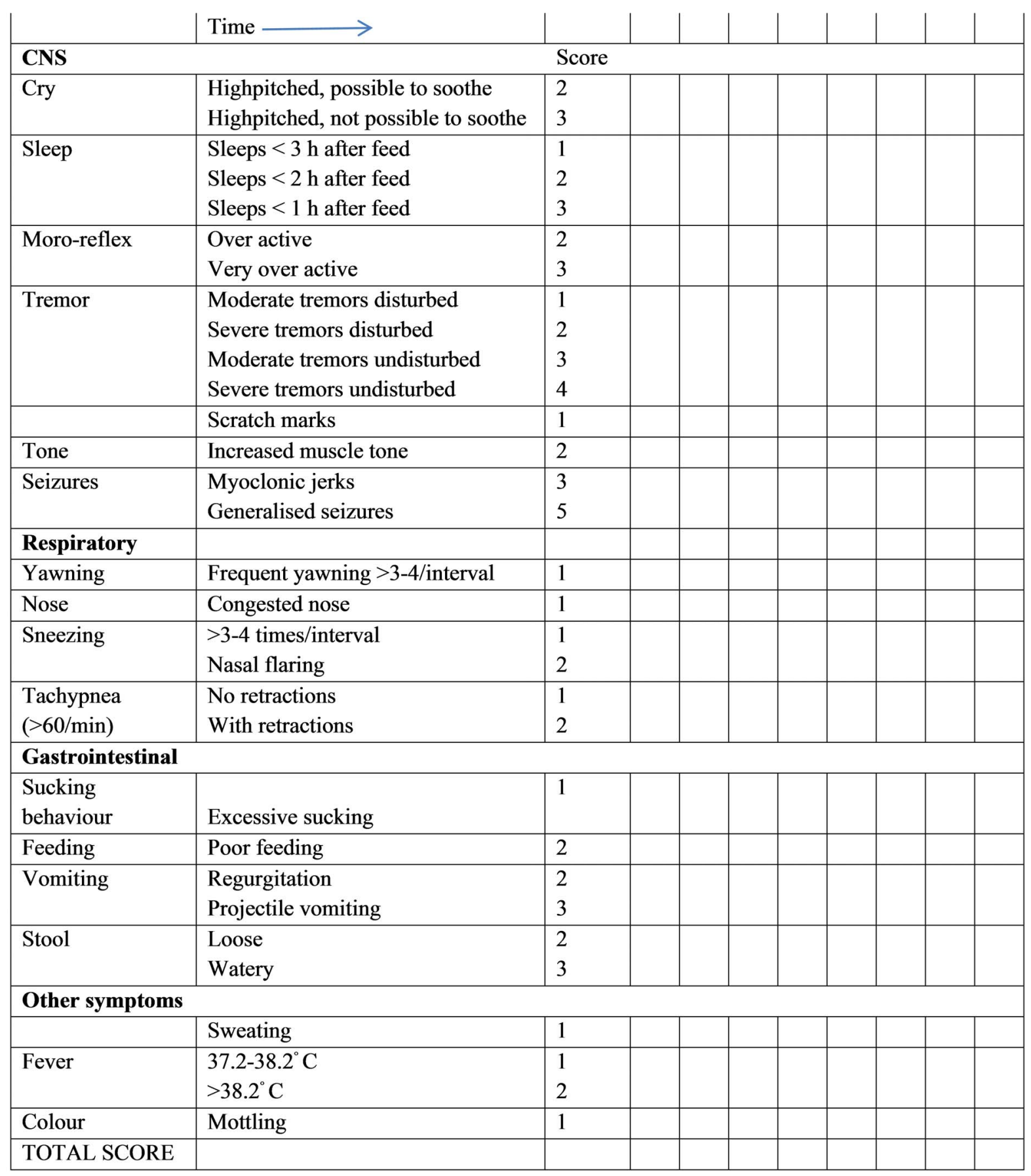

Figure 1. Neonatal Abstinance Score. Modified from Finnegan to Swedish, (Sarman 2000) here re-translated. doi:10.1371/journal.pone.0111327.g001

compared to all women who gave birth in the Stockholm area 2007 (23.9), 2008 (23.9) and 2009 (23.8).

A total of $48 \%$ of the women had 'other illnesses' documented in the prenatal care records. Most of these illnesses were mild and manageable, such as musculoskeletal problems, asthma, migraine, thyroid diseases or gastrointestinal reflux disease. Some were potentially serious such as obesity or chronic hepatitis. Eleven patients had more severe conditions such as diabetes mellitus, inflammatory bowel disease, serious or potentially serious pulmonary, rheumatic or neurological diseases.
Birth weight and head circumference did not differ between the four different exposure groups (Table 2). Linear regression adjusting for maternal age, maternal smoking in early pregnancy, gestational age and infant sex showed no statistical significance regarding birth weight $(\mathrm{p}=0.75)$. A model adjusting for only maternal smoking did not reach statistical significance. For head circumference the corresponding result was $\mathrm{p}=0.56$. A model adjusting for maternal smoking only did not show any statistically significant differences between the four antidepressant exposure groups. Prematurity (gestational age of 36 weeks and 6 days or less) was seen in $13 \%$ of the infants exposed to citalopram (Table 2). In 
Table 1. Characteristics of study population, women with antidepressant treatment and delivery at Karolinska University Hospital Huddinge Jan 2007 to June 2009.

\begin{tabular}{|c|c|c|c|c|c|}
\hline & $\begin{array}{l}\text { All } \\
\text { antidepressants }\end{array}$ & Citalopram & Sertraline & Fluoxetine & Other antidepressants** \\
\hline & $\mathbf{n}=\mathbf{2 2 0}$ & $n=77(35 \%)$ & $n=76(35 \%)$ & $n=34(15 \%)$ & $n=33(15 \%)$ \\
\hline Age of mother at delivery mean (years) & 31.2 & 31.2 & 32.1 & 29.4 & 31.0 \\
\hline \multicolumn{6}{|l|}{ Maternal psychiatric diagnosis ${ }^{\neq}(\mathrm{n})$} \\
\hline Depression & 168 & 59 & 58 & 29 & 22 \\
\hline Anxiety disorder & 80 & 29 & 27 & 8 & 16 \\
\hline Other psychiatric diagnoses $\neq \neq$ & 34 & 7 & 12 & 10 & 5 \\
\hline \multicolumn{6}{|l|}{ Tobacco in early pregnancy* $(\mathrm{n}[\%])$} \\
\hline No smoking & $189(86 \%)$ & $69(90 \%)$ & $62(82 \%)$ & $29(85 \%)$ & $29(88 \%)$ \\
\hline$<10$ cigarettes per day & $25(11 \%)$ & $7(9 \%)$ & $11(14 \%)$ & $4(12 \%)$ & $3(9 \%)$ \\
\hline$>10$ cigarettes per day & $4(2 \%)$ & $1(1 \%)$ & $2(3 \%)$ & $1(3 \%)$ & \\
\hline Snuff & $2(1 \%)$ & & $1(1 \%)$ & & $1(3 \%)$ \\
\hline \multicolumn{6}{|l|}{ Employment status* (n [\%]) } \\
\hline Full time employed & $87(40 \%)$ & $32(42 \%)$ & $33(43 \%)$ & $9(26 \%)$ & $13(39 \%)$ \\
\hline Part time employed & $54(25 \%)$ & $19(25 \%)$ & $18(24 \%)$ & $5(15 \%)$ & $12(36 \%)$ \\
\hline Unemployed & $72(33 \%)$ & $23(30 \%)$ & $23(30 \%)$ & $18(53 \%)$ & $8(24 \%)$ \\
\hline Missing data & $7(3 \%)$ & $3(4 \%)$ & $2(3 \%)$ & $2(6 \%)$ & \\
\hline Body mass index $x^{*}$ mean $\left(\mathrm{kg} / \mathrm{m}^{2}\right)$ & 24.4 & 24.0 & 24.7 & 24.9 & 24.1 \\
\hline Other illnesses* (n [\%]) & $106(48 \%)$ & $33(43 \%)$ & $42(55 \%)$ & $12(35 \%)$ & $19(58 \%)$ \\
\hline Antidepressant dose in third trimester*** median (range) (mg) & NA & $20(5-80)$ & $50(5-200)$ & $30(10-80)$ & NA \\
\hline Use of benzodiazepine during pregnancy $(\mathrm{n}[\%])$ & $14(6 \%)$ & $4(5 \%)$ & $5(7 \%)$ & $3(9 \%)$ & $2(6 \%)$ \\
\hline Use of other medications during pregnancy ( $[\%])$ & $136(62 \%)$ & $43(56 \%)$ & $44(58 \%)$ & $27(79 \%)$ & $22(67 \%)$ \\
\hline \multicolumn{6}{|l|}{ Mode of delivery ( $[\%]$ ) } \\
\hline Vaginal delivery & 155 (70\%) & $57(74 \%)$ & $48(63 \%)$ & $25(74 \%)$ & $25(76 \%)$ \\
\hline Cesarean section (planned) & $24(11 \%)$ & 7 (9\%) & $11(14 \%)$ & $2(6 \%)$ & $4(12 \%)$ \\
\hline Cesarian section (acute) & $20(9 \%)$ & $5(6 \%)$ & $9(12 \%)$ & $4(12 \%)$ & $2(6 \%)$ \\
\hline Vacuum extraction & $21(10 \%)$ & $8(10 \%)$ & $8(11 \%)$ & $3(9 \%)$ & $2(6 \%)$ \\
\hline
\end{tabular}

$\neq$ one patient can have more than one diagnosis.

$\neq \neq$ other psychiatric diagnoses, all antidepressants ( $n$ ): Phobia (4), Post-traumatic stress disorder (4), Eating disorder (9), Personality disorder (6), Obsessive compulsive disorder (7), Bipolar disorder type II (1), Attention deficit hyperactivity disorder (3).

*stated by mother at interview with midwife in prenatal care center, gestational week 10-14.

**other antidepressants $(n=33)$ : escitalopram (13 patients), venlafaxine (11), paroxetine (8) and duloxetine (1).

***Highest dose in maternal care records during third trimester.

NA = not applicable.

doi:10.1371/journal.pone.0111327.t001

a logistic regression model adjusting for maternal age, maternal tobacco use in early pregnancy and infant sex there were no statistically significant differences regarding prematurity between citalopram exposed infants $(13 \%)$ and infants exposed to sertraline $(7 \%, \mathrm{p}=0.85)$, fluoxetine $(9 \%, \mathrm{p}=0.67)$ or other antidepressants $(3 \%, \mathrm{p}=0.30)$.

Hypoglycemia in the neonate was defined as a blood glucose level $<2.6 \mathrm{mmol} / \mathrm{L}$. Hypoglycemia was diagnosed in $42(19 \%)$ of all study infants. A logistic regression model (adjusting for 5 min Apgar, gestational age, tobacco use in early pregnancy and infant sex) showed significantly more infants with at least one hypoglycemic episode in the fluoxetine group, $12(35 \%)$, compared to 8 $(10 \%)$ in the citalopram group, $\mathrm{p}=0.01$. There were no significant differences between citalopram exposed infants and infants exposed to sertraline $(p=0.74)$ or other antidepressants $(p=0.70)$. A model adjusting for only 5 min Apgar and gestational age did not add further information.
The blood glucose values of all hypoglycemic infants $(n=42)$ ranged from 1.0 to $2.5 \mathrm{mmol} / \mathrm{L}$ (mean $2.0 \mathrm{mmol} / \mathrm{L}$ ). In hypoglycemic infants exposed to citalopram $(n=8)$ the mean blood glucose was 2.0 (range 1.4 to 2.3 ). These numbers for hypoglycemic infants exposed to sertraline, fluoxetine and other antidepressants were 1.9 (range 1.0 to 2.5), 1.9 (range 1.0 to 2.5) and 2.1 (range 1.1 to 2.5) respectively. There were no significant differences between the groups, $\mathrm{p}=0.6$ (Kruskal Wallis).

Respiratory disorders included 'respiratory distress syndrome of newborn', 'transient tachypnea of newborn', 'other respiratory distress of newborn', pneumothorax, persistent fetal circulation and 'condition originating in the perinatal period', the latter an apneoic event. There were 14 cases $(6.3 \%)$ of respiratory disorders and 4 of them were in prematurely born infants. No significant correlation was seen between occurrence of respiratory disorders and type of antidepressant exposure in third trimester, in logistic regression adjusting for $5 \mathrm{~min}$ Apgar score and gestational age (in weeks), $\mathrm{p}=1.0$. 
Table 2. Neonatal characteristics of infants exposed to antidepressants in utero, born 1 Jan 2007 to 30 June 2009 at Karolinska University Hospital.

\begin{tabular}{|c|c|c|c|c|c|}
\hline & All antidepressants & Citalopram & Sertraline & Fluoxetine & Other antidepressants*** \\
\hline & $\mathbf{n}=\mathbf{2 2 0}$ & $n=77$ & $n=76$ & $n=34$ & $n=33$ \\
\hline Sex (male:female) (n[\%]) & 106:114 [48:52] & $38: 39$ [49:51] & $36: 40$ [47:53] & $16: 18$ [47:53] & $16: 17[48: 52]$ \\
\hline \multicolumn{6}{|l|}{ Gestational age (weeks) } \\
\hline mean $[95 \% \mathrm{Cl}]$ & $38.5[38.3$ to 38.7$]$ & $38.2[37.8$ to 38.5$]$ & $38.8[38.4$ to 39.1$]$ & $38.6[38.1$ to 39.1$]$ & $38.5[38.0$ to 39.1$]$ \\
\hline range & $31-42$ & $31-41$ & $32-41$ & $35-42$ & $34-42$ \\
\hline Prematurity $(\mathrm{n}[\%]) *$ & 19 [9] & 10 [13] & $5[7]$ & 3 [9] & 1 [3] \\
\hline \multicolumn{6}{|l|}{ Birth weight (gram) } \\
\hline mean $[95 \% \mathrm{Cl}]$ & 3386 [3314 to 3458$]$ & 3302 [3177 to 3425$]$ & $3476[3352$ to 3600$]$ & 3385 [3217 to 3553$]$ & 3377 [3167 to 3588$]$ \\
\hline range & 1790-5015 & 1790-4315 & 1905-5015 & 2110-4670 & 2305-4615 \\
\hline \multicolumn{6}{|l|}{ Head circumference $(\mathrm{cm})$} \\
\hline $\mathrm{n}$ & 217 & 75 & 75 & 34 & 33 \\
\hline mean $[95 \% \mathrm{Cl}]$ & $34.3[34.1$ to 34.5$]$ & $34.0[33.6$ to 34.4$]$ & $34.4[34.1$ to 34.8$]$ & $34.3[33.7$ to 34.8$]$ & $34.5[33.9$ to 35.1$]$ \\
\hline range & $28-38$ & $28-37.5$ & $31-38$ & $30-37$ & $31-37.5$ \\
\hline Hypoglycemia (n [\%]) & $42[19]^{\dagger}$ & $8[11]$ & $15[20]$ & $12[35]$ & $7[21]$ \\
\hline Respiratory diagnosis (n [\%]) & 14 [6] & 5 [6] & 5 [7] & $2[6]$ & 2 [6] \\
\hline Jaundice (n [\%]) & $10[5]$ & $5[6]$ & $3[4]$ & $1[3]$ & 1 [3] \\
\hline Neonatal care (n [\%]) & 29 [13] & 10 [13] & $9[12]$ & $6[18]$ & $4[12]$ \\
\hline
\end{tabular}

*gestational age $<37+0$.

**other antidepressants $(n=33)$ : escitalopram (13 patients), venlafaxine (11), paroxetine (8) and duloxetine (1).

† 0.02, statistical test (logistic regression, adjusting for gestational age, maternal tobacco use, infant sex and 5 min Apgar).

doi:10.1371/journal.pone.0111327.t002

There were five children with Apgar score $<7$ at five minutes of age.

Jaundice was diagnosed in 10 children (4 born prematurely). There were no significant differences between groups for antidepressant exposure, in a logistic regression model adjusting for 5 min Apgar and gestational age, $\mathrm{p}=1.0$.

One hundred and fifty-eight infants $(71 \%)$, received the diagnostic code Z001A 'healthy infant born in hospital'.

Twenty-nine $(13 \%)$ of the infants exposed to antidepressants were admitted to the neonatal ward. During 2007, 2008 and 2009, 13755 infants were born at Karolinska University Hospital Huddinge [14] and $1418(10.3 \%)$ of them admitted to the neonatal ward (data from Swedish Neonatal Quality Register). A univariate analysis showed no statistical difference between exposed and unexposed infants (born at Karolinska University Huddinge) regarding probability for neonatal admission $(p=0.16)$. Multivariate analysis (logistic regression adjusting for 5 min Apgar and gestational age) did not reveal any differences in admittance rates between the four exposure groups $(p=0.67)$.

No specific treatment for neonatal maladaptation syndrome was performed. The patients were treated with supportive care. Respiratory disorders were treated with CPAP (continuous positive airway pressure) if needed (8 cases) and hypoglycemia with intensified oral feeding, in some instances with i.v glucose, depending on the severity of the condition.

A total of 205 infants $(93 \%)$ were scored with Neonatal Abstinence Score sheet (table 3). The mean time at 'peak score' i e highest recorded score in patients who had a score of four or higher at any time, was for infants exposed to citalopram 31.6 hours (range 2-90; SD 21.4), for sertraline exposure 37.4 (1-84; 21.7), fluoxetine exposure $37.1(4-74 ; 21.3)$ and other antidepressants exposure 22.1 hours $(3-64 ; 17.6)$. There were no statistically significant differences between the groups (Kruskal Wallis, $\mathrm{p}=0.07$ ).

CNS symptoms contributed with on average $67 \%$ of the points in the group with severe abstinence (two or more scores of eight or higher) and 58\% in the group with mild abstinence (two or more scores of four or higher). Infants exposed to citalopram had mild abstinence in 18 cases (25\%), severe abstinence in two cases. Comparing citalopram to sertraline exposure in ordinal regression, adjusting for 5 min Apgar and infant sex, infants exposed to sertraline had an odds ratio of 1.08 (95\% confidence interval, 0.64 to 1.82). Odds ratio for fluoxetine compared to citalopram was 0.86 (95\% CI, 0.45 to 1.63 ) and for other antidepressants compared to citalopram 1.3 (95\% CI, 0.61 to 2.61). There were no significant differences in the occurrence of mild or severe abstinence between the different types of antidepressant exposure, adjusting for 5 min Apgar and infant sex, $\mathrm{p}=0.85$.

There were no significant differences in mean maternal SSRI dose in third trimester (analysis made for citalopram $[p=0.20]$, sertraline $[p=0.83]$ and fluoxetine $[p=0.18]$ ) between infants with or without abstinence (Mann Whitney U test).

Twenty-nine infants in the study were admitted to the neonatal ward. Twenty four percent of them were not scored with NAS compared to $4 \%$ of the infants who remained in the maternity ward $(p=0.0007)$.

\section{Discussion}

This study shows that a majority of all infants born to mothers with SSRI or SNRI treatment during pregnancy are healthy in the neonatal period. Only $3 \%$ developed a severe abstinence syndrome and $22 \%$ signs of mild abstinence, the symptoms mainly arising from the central nervous system. Our results are in accordance with other studies with similar or slightly higher 
Table 3. Analyses of Neonatal Abstinence Score in infants exposed to antidepressants in utero, born at Karolinska University Hospital Huddinge 1 Jan 2007 to 30 June 2009.

\begin{tabular}{|c|c|c|c|c|c|c|}
\hline & All antidepressants & citalopram & sertraline & fluoxetine & Other antidepressants $\not$ & $\mathbf{p}$ \\
\hline Scoring performed ( $\mathrm{n}[\%])$ & 205 [93\%] & $71[92 \%]$ & $71[93 \%]$ & $33[97 \%]$ & $30[91 \%]$ & $0.5^{\dagger}$ \\
\hline \multicolumn{7}{|c|}{ Number of scoring occasions } \\
\hline (mean [SD] [range]) & $8.4[3.0][2-27]$ & $8.5[2.7][3-18]$ & $8.4[2.9][2-20]$ & $8.4[4.4][2-27]$ & $8.3[2.2][5-13]$ & $0.66^{\dagger \dagger}$ \\
\hline \multicolumn{7}{|l|}{ Neonatal abstinence (n[\%]) } \\
\hline No abstinence & 152 [74\%] & $51[72 \%]$ & $53[75 \%]$ & 24 [73\%] & $24[80 \%]$ & \\
\hline Mild abstinence ${ }^{*}$ & $46[22 \%]$ & $18[25 \%]$ & 16 [23\%] & 7 [21\%] & $5[17 \%]$ & \\
\hline Severe abstinence $e^{* *}$ & $7[3 \%]$ & $2[3 \%]$ & $2[3 \%]$ & $2[6 \%]$ & $1[3 \%]$ & $0.85^{* * *}$ \\
\hline \multicolumn{7}{|c|}{$\begin{array}{l}* \text { two or more scorings of } 4-7 . \\
{ }_{* *}^{*} \text { two or more scorings of } 8 \text { or above. } \\
* * * \text { Multiple ordinal regression, adjusted for infant sex and } 5 \text { min Apgar. } \\
{ }^{\dagger} \text { Chi square test. } \\
{ }^{\dagger} \text { Kruskal Wallis. } \\
{ }^{*} \text { other antidepressants }(n=33) \text { : escitalopram (13 patients), venlafaxine (11), paroxetine (8) and duloxetine (1). } \\
\text { doi:10.1371/journal.pone. } 0111327 . t 003\end{array}$} \\
\hline
\end{tabular}

prevalence of the neonatal abstinence/maladaptation syndrome in infants with intrauterine SSRI/SNRI exposure. A study that used Finnegan score and similar definitions of severe and mild neonatal maladaptation syndrome found mild or severe neonatal maladaptation syndrome in $18 / 60(30 \%)$ infants exposed to SSRI, compared to $0 / 60$ control infants [12]. A slightly different definition of severe maladaptation (NAS score $>12$ or 3 scores $>8$ ) reported a prevalence of $4 \%$ in infants exposed to SSRI and $9 \%$ in infants exposed to venlafaxine [15]. Oberlander et al described symptoms of transient poor neonatal adaptation in $30 \%$ of a group of infants exposed to SSRI with or without the addition of clonazepam [16]. The reasons behind the differences in prevalence may be found in the different definitions of neonatal maladaptation syndrome as well as differences in study population (maternal age, socioeconomic status, health care, concomitant pharmacological treatment, use of tobacco and alcohol).

Hypoglycemia was common, $19 \%$ of all infants had blood glucose of $2.6 \mathrm{mmol} / \mathrm{L}$ or lower. Most of them were treated with intensified oral feeding. Other studies have found an association between prenatal antidepressant exposure and hypoglycemia [7]. The etiology behind this may be increased demands of energy in babies with abstinence. The prevalence reported in other studies have been lower, $1.4 \%$ in a register based cohort study [17] or 3/ 60 exposed infants in an Israeli cohort [12]. These large differences between studies may be explained by different definitions of hypoglycemia (the ICD-10 diagnosis of neonatal hypoglycemia, P70.4, requires blood glucose $2.2 \mathrm{mmol} / \mathrm{L}$ or lower) as well as differences in study protocols or in clinical practice. Hypoglycemia is also fairly common in all infants. In a clinical study of healthy term and preterm infants, $12 \%$ of the term and $14 \%$ of the preterm infants had a blood glucose of below $2.6 \mathrm{mmol} / \mathrm{L}$ during the first week of life [18]. In observational studies such as this one, the high rates of hypoglycemia may also be due to the fact that jitteriness and tremor can be perceived as symptoms of hypoglycemia leading to the measurement of blood glucose, increasing the chance of diagnosing a low blood glucose value. Hypoglycemia in infants is however a potentially serious condition $[19,20]$ and needs to be further investigated, preferably in a randomized controlled study. Until then, screening of blood glucose in neonates prenatally exposed to antidepressants should be considered.
The mothers in this study had a more unfavorable health status than the average pregnant Stockholm County population with regard to higher proportion of smokers and higher BMI. This may also affect neonatal outcome. The catchment area of Karolinska University Hospital Huddinge includes many socioeconomically constrained areas, often associated with higher BMI and a higher proportion of smokers. Any comparison between this catchment area and the rest of Stockholm County must be done with caution. Studies on infants to mothers with opioid use during pregnancy have shown increased risk of neonatal abstinence as well as other negative neonatal outcomes in opioid exposed infants where there was a concomitant heavy cigarette consumption [21]. Smoking cessation and control of weight gain during pregnancy may be an important method in this patient group to improve infant (and maternal) health.

Several other studies report a high incidence of respiratory symptoms in infants exposed to SSRIs [5,22]. However, some experts argue that the increased risk of neonatal complications that have been attributed to SSRI exposure may be due to confounding factors [23]. Fourteen neonates in this study had a respiratory diagnosis but the study design did not allow a comparison to an unexposed population.

Different antidepressants have different pharmacokinetic properties. This may, in theory, influence the timing of symptoms of abstinence or serotonergic overstimulation in exposed neonates. Time to peak value (NAS) was therefore analyzed but failed to show any significant differences between the groups. Individual factors such as metabolic and transporter capacity of SSRI/SNRI in mother and child as well as placenta may be of greater influence on the occurrence of maladaptation and timing of symptoms [15,24-26]. Time to peak value ranged between 2 and 90 hours suggesting that infants exposed to antidepressants may have a relatively late onset of peak abstinence symptoms. With today's extremely short duration of hospital stay for newborns, the symptoms may even occur after discharge from hospital. Karolinska University Hospital Huddinge, as well as several other hospitals, has abandoned the policy of advising parents of infants prenatally exposed to antidepressants to stay at least 72 hours. In uneventful deliveries, the mother and infant usually leave the maternity ward within 48 hours.

Seven percent of the infants in the study were not subject to abstinence scoring. This may be due to the fact that the midwife 
nurse was not aware of the guidelines, that the infant was perceived to be healthy or that the scoring sheet was not properly stored. Also, NAS is often used as a screening tool and may therefore be considered unnecessary in sick infants in the neonatal ward who are subjected to more sophisticated surveillance methods. This may explain why scoring was not performed in a larger proportion of the infants admitted to the neonatal ward compared to the maternity care units.

The causal relationship between SSRI or SNRI exposure and high scoring values in the NAS is of course not established in each infant included in this study. Other illnesses or prenatal risk factors, unrelated to pharmacological exposure or maternal illness, may contribute. This study could not investigate an increased risk of neonatal symptoms in infants prenatally exposed to antidepressants compared to unexposed ones.

It can be argued that we recruited a too small study population. There may have been differences between the exposure groups had they been larger. The retrospective design of the study and the changed policy of the hospital (Neonatal Abstinence Score and increased surveillance of all infants prenatally exposed to SSRIs were abandoned in July 2009) made it impossible to perform this study on a larger cohort. The retrospective design is of course an important limitation to this study. A prospective design would have allowed us to for example confirm antidepressant use and exposure in mother and infant.

Monitoring neonates with prenatal exposure to drugs and abuse substances is a delicate task. There is a risk that health care

\section{References}

1. Vesga-Lopez O, Blanco C, Keyes K, Olfson M, Grant BF, et al. (2008) Psychiatric disorders in pregnant and postpartum women in the United States. Arch Gen Psychiatry 65: 805-815.

2. Stephansson O, Granath F, Svensson T, Haglund B, Ekbom A, et al. (2011) Drug use during pregnancy in Sweden - assessed by the Prescribed Drug Register and the Medical Birth Register. Clin Epidemiol 3: 43-50.

3. Lennestal R, Kallen B (2007) Delivery outcome in relation to maternal use of some recently introduced antidepressants. J Clin Psychopharmacol 27: 607-613.

4. Jimenez-Solem E, Andersen JT, Petersen M, Broedbaek K, Andersen NL, et al. (2013) Prevalence of antidepressant use during pregnancy in Denmark, a nationwide cohort study. PLoS One 8: e63034.

5. Reis M, Kallen B (2010) Delivery outcome after maternal use of antidepressant drugs in pregnancy: an update using Swedish data. Psychol Med 40: 1723-1733.

6. Berard A, Ramos E, Rey E, Blais L, St-Andre M, et al. (2007) First trimester exposure to paroxetine and risk of cardiac malformations in infants: the importance of dosage. Birth Defects Res B Dev Reprod Toxicol 80: 18-27.

7. Moses-Kolko EL, Bogen D, Perel J, Bregar A, Uhl K, et al. (2005) Neonatal signs after late in utero exposure to serotonin reuptake inhibitors: literature review and implications for clinical applications. JAMA 293: 2372-2383.

8. Laine K, Heikkinen T, Ekblad U, Kero P (2003) Effects of exposure to selective serotonin reuptake inhibitors during pregnancy on serotonergic symptoms in newborns and cord blood monoamine and prolactin concentrations. Arch Gen Psychiatry 60: 720-726.

9. Kieler H, Artama M, Engeland A, Ericsson O, Furu K, et al. (2012) Selective serotonin reuptake inhibitors during pregnancy and risk of persistent pulmonary hypertension in the newborn: population based cohort study from the five Nordic countries. BMJ 344: d8012.

10. Bonari L, Pinto N, Ahn E, Einarson A, Steiner M, et al. (2004) Perinatal risks of untreated depression during pregnancy. Can J Psychiatry 49: 726-735.

11. Finnegan LP, Connaughton JF, Jr., Kron RE, Emich JP (1975) Neonatal abstinence syndrome: assessment and management. Addict Dis 2: 141-158.

12. Levinson-Castiel R, Merlob P, Linder N, Sirota L, Klinger G (2006) Neonatal abstinence syndrome after in utero exposure to selective serotonin reuptake inhibitors in term infants. Arch Pediatr Adolesc Med 160: 173-176.

13. Sarman I (2000) [Methadone treatment during pregnancy and its effect on the child. Better than continuing drug abuse, should be monitored by a specialized antenatal care center]. Lakartidningen 97: 2182-2184, 2187-2188, 2190. professionals are being too interventional, introducing unnecessary concern regarding the infant's health. There is also a risk, with antidepressants becoming increasingly common in the pregnant population- and considered 'safe'- that knowledge about potentially serious complications is lost. A modified Neonatal Abstinence Score could be useful in detecting abstinence/maladaptation in this group. The CNS and respiratory categories are probably more useful than the gastrointestinal category. Most important is however knowledge among care givers regarding the possible symptoms that can arise after prenatal exposure to antidepressants.

\section{Conclusions}

Severe abstinence in a cohort of infants exposed to SSRI/SNRI in late pregnancy was rare since it occurred in only $3 \%$ of the cases. Neonatal hypoglycemia was observed in $19 \%$ of the infants which is higher than previously reported. Admission to the neonatal ward was seen in $13 \%$ of the infants and did not differ significantly from the admittance rate in other infants born in the same hospital during the studied period.

\section{Author Contributions}

Conceived and designed the experiments: LF LN LLG KW. Performed the experiments: LF LN KW. Analyzed the data: LF LN LLG KW. Contributed reagents/materials/analysis tools: LF KW LN. Wrote the paper: LF LN LLG KW.

14. Socialstyrelsen (2013) Statistikdatabasen. In: Socialstyrelsen, editor. wwwsocialstyrelsense. www.socialstyrelsen.se.

15. Rampono J, Simmer K, Ilett KF, Hackett LP, Doherty DA, et al. (2009) Placental transfer of SSRI and SNRI antidepressants and effects on the neonate. Pharmacopsychiatry 42: 95-100.

16. Oberlander TF, Misri S, Fitzgerald CE, Kostaras X, Rurak D, et al. (2004) Pharmacologic factors associated with transient neonatal symptoms following prenatal psychotropic medication exposure. J Clin Psychiatry 65: 230-237.

17. Kallen B (2004) Neonate characteristics after maternal use of antidepressants in late pregnancy. Arch Pediatr Adolesc Med 158: 312-316.

18. Hawdon JM, Ward Platt MP, Aynsley-Green A (1992) Patterns of metabolic adaptation for preterm and term infants in the first neonatal week. Arch Dis Child 67: 357-365.

19. Boardman JP, Wusthoff CJ, Cowan FM (2013) Hypoglycaemia and neonatal brain injury. Arch Dis Child Educ Pract Ed 98: 2-6.

20. Duvanel CB, Fawer CL, Cotting J, Hohlfeld P, Matthieu JM (1999) Long-term effects of neonatal hypoglycemia on brain growth and psychomotor development in small-for-gestational-age preterm infants. J Pediatr 134: 492-498.

21. Winklbaur B, Baewert A, Jagsch R, Rohrmeister K, Metz V, et al. (2009) Association between prenatal tobacco exposure and outcome of neonates born to opioid-maintained mothers. Implications for treatment. Eur Addict Res 15: $150-156$.

22. Leibovitch L, Rymer-Haskel N, Schushan-Eisen I, Kuint J, Strauss T, et al. (2013) Short-Term Neonatal Outcome among Term Infants after in utero Exposure to Serotonin Reuptake Inhibitors. Neonatology 104: 65-70.

23. Warburton W, Hertzman C, Oberlander TF (2010) A register study of the impact of stopping third trimester selective serotonin reuptake inhibitor exposure on neonatal health. Acta Psychiatr Scand 121: 471-479.

24. Hilli J, Heikkinen T, Rontu R, Lehtimaki T, Kishida I, et al. (2009) MAO-A and COMT genotypes as possible regulators of perinatal serotonergic symptoms after in utero exposure to SSRIs. Eur Neuropsychopharmacol 19: 363-370.

25. Oberlander TF, Bonaguro RJ, Misri S, Papsdorf M, Ross CJ, et al. (2008) Infant serotonin transporter (SLC6A4) promoter genotype is associated with adverse neonatal outcomes after prenatal exposure to serotonin reuptake inhibitor medications. Mol Psychiatry 13: 65-73.

26. Ter Horst PG, Jansman FG, van Lingen RA, Smit JP, de Jong-van den Berg LT, et al. (2008) Pharmacological aspects of neonatal antidepressant withdrawal. Obstet Gynecol Surv 63: 267-279. 